\title{
Atividades de retextualização a partir do gênero discursivo memórias: proposta de trabalho em uma escola da comunidade remanescente quilombola de Furnas do Dionísio
}

\author{
Retextualization activities from the discursive gender memories: proposal for \\ working in a school of the remaining quilombola community of Furnas de \\ Dionísio
}

Ariane Wust de Freitas Francischini ${ }^{1}$

Universidade Estadual de Mato Grosso do Sul

Adriana Lúcia de Escobar Chaves de Barros $^{2}$

Universidade Estadual de Mato Grosso do Sul

\begin{abstract}
- RESUMO: Este estudo é parte de uma pesquisa do Programa de Mestrado Profissional em Letras em Rede - PROFLETRAS, intitulada "Atividades de retextualização a partir do gênero discursivo memórias: proposta de trabalho em uma escola da comunidade remanescente quilombola de Furnas do Dionísio". Com a finalidade de registrar e revitalizar a identidade cultural da comunidade, propomos um trabalho com sequência didática - SD, aplicada em uma turma do $9^{\circ}$ ano do ensino fundamental da Escola Estadual Zumbi dos Palmares, localizada na comunidade remanescente quilombola de Furnas do Dionísio, no município de Jaraguari/MS, sendo o corpus de análise formado pelos textos produzidos e retextualizados pelos alunos a partir de relatos orais de idosos da comunidade. Ao considerarmos a língua como um conjunto de práticas sociais e cognitivas historicamente situadas, cuja nascente emerge na interação entre os sujeitos e tomando por base o contínuo da relação entre oralidade e escrita proposta por Marcuschi, procuramos explicitar como essas modalidades se complementam. E para a construção do conceito de gênero discursivo, tomamos por base as considerações sobre os estudos do pensador russo Bakhtin.
\end{abstract}

- PALAVRAS-CHAVE: Oral. Escrita. Linguagem. Comunicação. Gênero. Memórias.

- ABSTRACT: This study is part of a research of the Professional Master's Program in Network Letters - PROFLETRAS, entitled "Retextualization activities from the discursive gender memories: proposal for working in a school of the remaining quilombola community of Furnas de Dionísio." In order to register and revitalize the cultural identity of the community, we propose a work with a didactic sequence - SD, applied in a 9th grade class of the Zumbi dos Palmares State School, located in the remaining quilombola community of Furnas do Dionísio, in the municipality of Jaraguari / MS, with a corpus of analysis formed by texts produced and retextualized by students from oral reports of elderly community. Considering language as a set of historically situated social and cognitive practices, whose source emerges in the interaction between the subjects and based on the continuum of the relationship between orality and writing proposed by Marcuschi, we try to explain how these modalities complement each other. For the construction of the concept of discursive gender, we take as basis the considerations on the studies of the Russian thinker Bakhtin.

- KEYWORDS: Oral. Writing. Language. Communication. Genre. Memories.

\footnotetext{
1 Mestranda em Letras pela UEMS. Graduada em Letras, pós-graduada em Metodologia do Ensino Superior, Educação á Distancia, Coordenação Pedagógica. aajaraguari@hotmail.com

${ }^{2}$ Pós-Doutora em Letras Modernas pela USP. Graduada em Letras, pós-graduação em Metodologia do Ensino da Língua Inglesa, Management (MBA) pelo IAG Escola de Negócios, Mestre em Administração de Empresas com especialização em Marketing pelo IAG Escola de Negócios, Doutora em Estudos da Linguagem. chaves.adri@hotmail.com
} 


\section{Introdução}

Este estudo é parte de uma pesquisa do Programa de Mestrado Profissional em Letras em Rede - PROFLETRAS, intitulada "Atividades de retextualização a partir do gênero discursivo memórias: proposta de trabalho em uma escola da comunidade remanescente quilombola de Furnas do Dionísio".

Ao considerarmos a língua como um conjunto de práticas sociais e cognitivas, historicamente situadas, cuja nascente emerge na interação entre os sujeitos, buscamos nesta pesquisa propor um trabalho de retextualização da modalidade oral para a escrita da língua portuguesa, por meio de atividades com gêneros discursivos memórias, a fim de, revitalizar a identidade cultural da comunidade remanescente quilombola de Furnas do Dionísio. Com isso, buscamos também contribuir para a prática da autoria e da autonomia dos alunos de uma turma de $9^{\circ}$ ano membros desta comunidade, subsidiá-los na compreensão do gênero memórias e na retextualização da fala para a escrita, além de estabelecer relações pedagógicas em sala de aula, para que haja interação entre os sujeitos e em consequência a aprendizagem seja mais significativa para o aluno.

Neste contexto procuramos compreender o que é memória, sua importância para o registro escrito da língua falada e da valorização da identidade cultural deste povo, bem como realizar atividades por meio da aplicação de uma sequência didática SD, a fim de, instrumentalizar os processos de progressão do ensino na expressão da linguagem oral e escrita na aula de Língua Portuguesa. De acordo com as perspectivas teóricas das relações linguístico-discursivas e tomando por base o contínuo da relação entre oralidade e escrita proposta por Bakthin, Marcuschi, Scheneuwly e Dolzs entre outros, procuramos entender com base nas análises das memórias retextualizadas, como essas práticas se complementam.

É oportuno mencionar que a Escola Estadual Zumbi dos Palmares têm como princípio, a inserção de metodologias ativas e formação integral do aluno. $\mathrm{O}$ trabalho realizado nesta pesquisa será de âmbito interdisciplinar, uma parceria entre os professores, alunos e guardiões das memórias, esses últimos chamados assim, por serem os membros mais antigos da comunidade.

Neste estudo abordaremos duas problemáticas: uma relacionada ao ensino de língua portuguesa e outra específica da comunidade quilombola onde os sujeitos da pesquisa estão inseridos.

Cabe salientar que a perpetuação do discurso ideológico e conservador da valorização da escrita em detrimento da fala, ou seja, do poder atribuído a um sujeito, grupo ou sociedade que domina a escrita, colaborou para manter um ensino restrito à gramática de norma padrão, além de desprestigiar o uso oral da língua nas práticas cotidianas. Além disso, as histórias orais da comunidade investigada correm o risco de desaparecer, caso não sejam registradas adequadamente, propomos nesta pesquisa registrar os aspectos culturais e identitários destes indivíduos, com base nas lembranças dos membros mais antigos.

Para tanto, elegemos o gênero memórias por apresentar características de uso da língua nas modalidades oral e escrita, que será uma oportunidade à aplicação de atividades envolvendo os processos de retextualização "da fala para a escrita", que é o objeto central desta pesquisa.

Elaboramos uma sequência didática - SD, que foi aplicada em uma turma do $9^{\circ}$ ano do ensino fundamental da Escola Estadual Zumbi dos Palmares, localizada na comunidade remanescente quilombola de Furnas do Dionísio, no município de 
Jaraguari/MS, sendo o corpus de análise formado pelos textos produzidos e retextualizados pelos alunos a partir de relatos orais de idosos da comunidade.

Consideramos relevante apresentar neste artigo, algumas abordagens teóricas que respaldaram a aplicação das atividades práticas na SD e contextualizar o objeto, campo e os sujeitos da pesquisa.

\section{Fala e escrita: duas modalidades da língua em uso nas práticas sociais}

Partindo do princípio que comunicar-se oralmente ou por escrito pode e deve ser ensinado sistematicamente na escola, compreendemos que é a intenção comunicativa que funda o uso da língua, sendo considerado um conjunto de práticas sociais e cognitivas historicamente situadas, cuja nascente emerge na interação entre os sujeitos. Falar e escrever bem é ser capaz de usar adequadamente a língua para produzir um efeito de sentido pretendido numa dada situação.

Segundo Marcuschi (2010, p. 17) a oralidade e a escrita são práticas e usos da língua com características próprias, mas não suficientemente opostas para caracterizar dois sistemas linguísticos em uma dicotomia, tanto na oralidade quanto na escrita somos capazes de elaborar discursos coesos, coerentes, exposições formais e informais.

A oralidade e a escrita não são dois sistemas linguísticos diferentes, mas duas modalidades da língua, ou seja, uma nova concepção de língua e texto como um conjunto de práticas sociais.

A fala é adquirida naturalmente desde a infância em contextos informais, estabelecidas nas práticas orais, relações sociais e dialógicas. Enquanto a escrita é adquirida em contextos formais, como a escola, acreditamos que isso colabore para que ela tenha maior prestígio em relação à fala.

Conforme afirma Marcuschi (2010), elas possuem os mesmos traços: dialogicidade, usos estratégicos, funções interacionais, envolvimento, negociação, situacionalidade, coerência e dinamicidade. Entretanto, as diferenças entre as duas modalidades ocorrem dentro de um continuum tipológico e precisam ser vistas na perspectiva do uso e não como características intrínsecas.

Para Marcuschi (2010, p 16), são as formas que se adequam aos usos e não o inverso, trata-se de uma análise de uso e práticas sociais da língua e não de formas abstratas. Sem dúvida a evolução da tecnologia da escrita contribuiu para facilitar os registros das atividades humanas em que o uso da língua é compreendido como uma prática social: registro de documentos, trabalhos científicos, narração de fatos, notícias, reportagens entre outros.

Para aplicarmos a intervenção pedagógica em sala de aula de Língua Portuguesa no ensino fundamental, que é um dos critérios estabelecidos pelo Programa de Mestrado em Letras em Rede, elegemos o gênero memórias por apresentar características de uso da língua nas modalidades oral e escrita, que será uma oportunidade para a aplicação de atividades envolvendo os processos de retextualização "da fala para a escrita", que é o objeto central desta pesquisa.

\section{Abordagens dobre o gênero discursivo Memórias}

Destacamos o dialogismo como princípio fundador da linguagem. A partir disto consideramos os gêneros como um enunciado responsivo e relativamente estável. Para o autor cada campo da atividade humana vai servir-se da língua a partir de interesses e finalidades específicas, produzindo enunciados que serão organizados de maneiras diversas. Cada esfera de utilização da língua elabora seus tipos relativamente 
estáveis de enunciados, evidenciando o que denominamos Gêneros do Discurso (Bakhtin 2004, p.123).

A concepção de língua, em Bakhtin é discursiva vinculada às esferas sociais e aos valores ideológicos, um ato social relacionado ao uso da linguagem nos diversos campos da atividade humana. Considerando que o fenômeno da interação verbal é estabelecido por meio de enunciados e enunciações, os estudos de Bakhtin reforçam o caráter dialógico e interacional da língua, refletidos na produção de enunciados concretos que se materializam em diferentes gêneros discursivos. Para o autor (2004, p.95) a língua, no seu uso prático é inseparável de seu conteúdo ideológico ou relativo à vida e não poderá ser reduzida a um sistema abstrato.

De acordo com os princípios bakhtinianos sobre gêneros, podemos definir memória como atividade humana que requer o uso da linguagem interacional, com propósito comunicativo e contexto situacional definido. No processo interacional os sujeitos conversam, recuperam fatos anteriores, memórias e ao mesmo tempo refletem questões futuras, ou seja, a ideia do dialogismo se faz presente em textos/discursos passados ou novos e nunca isolados.

Nos estudos sobre Gêneros, Bakhtin categoriza-os como discursivos, enquanto Marcuschi como textuais. Apoiados em Bakhtin e Marcuschi, entendemos que os gêneros discursivos são constitutivos de três elementos, conteúdo temático, estilo e construção composicional que são determinados pelas especificidades de cada campo de atuação.

Neste aspecto, consideraremos as memórias de narrativas de vida como gêneros discursivos memórias devido ao estilo. Para Bakhtin (2011, p. 266), os estilos de linguagem ou funcionais não são outra coisa, senão estilos de gênero de determinadas esferas da atividade humana e da comunicação.

Quando falamos em gênero memória logo remetemos ao conceito de exposição de fatos pessoais ou relatos históricos inventivos ou reais. É certo que a temática memória instigou pesquisadores de diferentes tempos e sociedades por se tratar de acontecimentos históricos e culturais estabelecidos nas práticas sociais e transcritas em produções discursivas orais ou escritas.

As narrativas pessoais, memórias, desempenham um papel poderoso como artefatos mediadores na medida em que as identidades são formadas e reformadas e esse processo é mostrado por meio da linguagem, da oralidade para o registro escrito.

\section{Contextualização da pesquisa}

O objetivo desta pesquisa é propor um trabalho de retextualização da modalidade oral para a escrita da língua portuguesa, por meio de atividades com gêneros discursivos memórias, a fim de, revitalizar a identidade cultural da comunidade quilombola de Furnas do Dionísio, contribuir para a prática da autoria e da autonomia dos alunos de uma turma de $9^{\circ}$ ano membros desta comunidade, subsidiá-los na compreensão dos gêneros memórias e na retextualização da oralidade para a escrita, estabelecer relações pedagógicas em sala de aula, para que haja interação entre os sujeitos e em consequência a aprendizagem seja mais significativa para o aluno.

O público alvo deste estudo são quatorze alunos de uma turma de $9^{\circ}$ ano e três anciões da comunidade, tratados nesta pesquisa como os "guardiões das memórias".

Temos como locus a Escola Estadual Zumbi dos Palmares, localizada na comunidade remanescente quilombola de Furnas do Dionísio no município de Jaraguari, estado de Mato Grosso do Sul, criada pelo Decreto n. ${ }^{\circ} 8.408$ de 20/12/1995, publicado no Diário Oficial n. ${ }^{\circ} 4.184$ de 21/12/1995. 
Segundo dados da Fundação, no Estado de Mato Grosso do Sul existem registros de vinte e duas comunidades quilombolas, que fazem parte do contexto histórico, social e cultural e que durante muito tempo permaneceram segregadas e estigmatizadas socialmente. São comunidades construídas a partir de um padrão de vida, baseado em aspectos geográficos, históricos e por laços familiares. Neste sentido destacamos a comunidade remanescente quilombola de "Furnas do Dionísio", localizada na área rural do município de Jaraguari/MS.

As pesquisadoras Bandeira e Dantas (1997, p.34) realizaram um estudo antropológico que resultou no reconhecimento desta comunidade como remanescente quilombola, "tendo como princípio a cooperação, a reciprocidade e o igualitarismo, a comunidade negra de Furnas de Dionísio construiu a concepção de tempo e de espaço indissociavelmente vinculada à liberdade".

A ocupação da área por Dionísio e seus descendentes remonta à segunda metade do século XIX. As furnas (altos morros que se destacam do maciço de Maracaju) são identificadas pelos nomes dos troncos familiares da comunidade e em cuja base ou proximidade localizam-se as moradias de seus descendentes.

Vivem na comunidade aproximadamente 300 (trezentas) pessoas que sobrevivem da agricultura familiar, venda de melado, rapadura, farinha de mandioca, criação de animais e funcionalismo público. A comunidade mantém algumas culturas dos tempos dos seus ancestrais, como a dança do engenho novo, a catira, a capoeira e a cobrinha.

No que diz respeito às práticas religiosas observamos a devoção da comunidade a Santo Antônio, sendo a festa local mais tradicional, mas também fazem devoções a São Benedito, Santa Luzia, Santa Bárbara, Nossa Senhora do Rosário, Santa Luzia, São João e São Sebastião.

O culto aos mortos, como respeito aos antepassados, faz do cemitério um lugar sagrado, envolvendo crenças e ritos, "para manter os limites entre o visível e o invisível, pratica-se o rito de acender uma vela no local onde se deu a morte e mantê-la acessa durante sete dias e sete noites, findo o período de resguardo das fronteiras entre a vida e a morte, a vela é levada ao cemitério" (BANDEIRA e DANTAS 1997, p.72).

As raízes históricas das comunidades remanescentes quilombolas se entrelaçam com a própria história do Brasil que desde o início do processo de colonização contribuiu para a segregação social deste povo, que ao longo da história lutou pela implantação de politicas públicas para a equiparação das desigualdades sociais, mas que infelizmente ainda permaneceu a margem da sociedade, passando por um processo de exclusão, submissão e de esquecimento.

É neste contexto que visualizamos a trajetória e o processo de formação das comunidades quilombolas brasileiras, que foram submetidas tanto por demarcações territoriais, quanto pelas fronteiras simbólicas impostas pelo percurso histórico, social, político e cultural.

Assim como as demais comunidades renascentes quilombolas espalhadas pelo país, Furnas do Dionísio surgiu a partir da necessidade de fixação territorial de um grupo étnico, escravos fugidos, que se adentravam pelas florestas brasileiras e procuravam espaços de difícil acesso que serviriam de esconderijo e proteção, que também foram usadas como limiares simbólicos de separação entre os povos de dentro e de fora, colonizadores e escravos desertores. No caso específico desta comunidade os limiares foram estabelecidos por questões geográficas oportunas, furnas e cerras que circundam e demarcam os territórios.

O trabalho com histórias orais de uma comunidade tradicional poderá contribuir para a transposição dos limiares historicamente e socialmente impostos. As 
histórias orais são instrumentos de preservação e transmissão de heranças identitárias e culturais de uma comunidade linguística. Por meio delas é possível identificar um universo de representações de um grupo social, as situações cotidianas e as vivências dos narradores. Castoriadis (1982) considera que a linguagem e outros sistemas simbólicos são os mediadores nas representações da realidade dos sujeitos. Assim a memória narrativa é um processo memorável em que os indivíduos são constituídos pelas histórias que contam e pelas experiências que vivenciam.

\section{Processo de retextualização do gênero textual memória}

De acordo com Marcuschi (2010, p.45) a expressão retextualização foi emprega pela primeira vez em 1993 por Travaglia, em sua tese de doutorado, ao referirse sobre a tradução de uma língua para outra.

Ao usar o termo retextualização Marcuschi (2010. p.46) procurou representar o uso da língua de uma modalidade para outra, por meio de operações realizadas na passagem do texto falado para o texto escrito.

Já as autoras Raquel S. Fiad, Maria Laura Mayrink - Sabison (1991) e Maria Bernadete Abaurre et al (1995) utilizaram as expressões refacção e reescrita no trabalho de reescrita, escrita para escrita, de um mesmo texto. Não se trata de operações de retextualização como apresentada por Marcuschi (2010, p. 47), visto que a reescrita acontece dentro de um mesmo texto e a retextualização dar-se da modalidade oral para a escrita, "portanto, a passagem da fala para a escrita não é a passagem do caos para a ordem: é a passagem de uma ordem para outra ordem".

Neste estudo adotamos a passagem do texto falado para o texto escrito, utilizando os operadores discursivos apresentados por Marcuschi (2010 p.75), a fim de demonstrar que as duas modalidades atendem a propósitos comunicativos diferentes de acordo com a necessidade de interação dos sujeito

Além do que se considerarmos fala e escrita e suas respectivas combinações teríamos quatro possibilidades de retextualização: fala/escrita, fala/fala, escrita/fala e escrita/escrita.

Para Matencio (2002) retextualização é uma atividade que implica a produção de um novo texto a partir de um ou mais textos-base, conforme Guimarães Silva e Matencio (2005, p. 246) envolverá relações entre gêneros e textos (intertextualidade) e entre discursos (interdiscursividade). Esta etapa prevê a passagem da língua falada para a escrita, da transcrição da oralidade para a norma padrão da língua portuguesa. Porém não podemos deixar de mencionar a complexidade desta atividade, visto que as escolhas dos registros escrito poderão influenciar na produção final do sentindo do texto.

Organizamos uma sequência didática com o gênero textual memórias que proporcionou novas práticas de linguagem ainda não dominadas pelos alunos. Essa sequência didática fundamentou-se na concepção de Schneuwly (2004, p. 41) na qual esclarece que os saberes escolares precisam de uma didatização, uma transposição didática para que este objeto de ensino passe por planejamento e reformulação.

Desse modo, entendemos que a aplicação desse procedimento didático, no âmbito do ensino de língua portuguesa, corresponde à organização das aulas a partir de um conjunto de atividades, tais como leitura, escrita, oralidade e análise linguística.

Com a finalidade de alcançar os objetivos propostos neste estudo, utilizamos como metodologia a aplicação de uma sequencia didática (SD). Para Dolz e Schewly (2004, p.82) a sequência didática é um conjunto de atividades de ensino organizadas de maneira sistemática em torno de um gênero textual oral ou escrito. 
A SD possibilitará aos alunos, por meio da aplicação de atividades organizadas e sequenciadas, o acesso a práticas de linguagens novas ou ainda não domináveis, além conduzir para a progressão do ensino na expressão oral e escrita da língua portuguesa. Cabendo durante todo o processo de aplicação a possibilidade de construção e reconstrução das práticas metodológicas propostas.

Devemos destacar que todas as atividades sugeridas na SD, foram elaboradas de acordo com os conteúdos propostos no Referencial Curricular do Estado de Mato Grosso do Sul, língua portuguesa, nono ano do Ensino Fundamental, com a finalidade de desenvolver as competências e Habilidades de oralidade, prática de leitura, produção de texto, análise e reflexão sobre a língua (Referencial Curricular/MS 2012, p.128 e 129).

Partindo do princípio de que gênero textual memórias é de esfera social e sequência tipológica narrativa, buscamos proporcionar meios que ajudassem os alunos do $9^{\circ}$ ano da escola estadual Zumbi dos Palmares, adquirirem habilidades da escrita e da fala para melhorar o desenvolvimento de sua competência discursiva.

\section{Etapas da Sequência didática:}

$1^{\circ}$ Momento: Apresentação da proposta

Para esta etapa utilizamos três aulas de Língua Portuguesa, nas quais os alunos assistiram ao filme "Narradores de Javé", de Eliane Caffé, lançado em 2004, realizaram um debate direcionado pela professora sobre a temática abordada e associada à pesquisa de campo proposta.

$2^{\circ}$ Momento: Estudo das histórias orais

Conforme esclarece Charaudeau (2004, 326), "Qualquer gênero de discurso mantém uma relação com a memória: certos enunciados são conservados, outros não, e as modalidades de sua conservação são inseparáveis de sua identidade". Logo, pensar em gêneros marcados pelo modo narrativo do discurso remete também à ideia da memória, já que Narradores de Javé: uma análise do discurso fílmico, contar histórias pode ser uma maneira de possibilitar o compartilhamento de lembranças, por meio de encontros e reencontros entre passado e presente.

Os alunos assistiram ao filme "Narrador de Javé", de Eliane Caffé, lançado em 2004, com objetivo de demonstrar as práticas e narrativas orais como fenômenos sociais. Este estudo teve como foco o registro das narrativas de memórias da comunidade quilombola "Furnas do Dionísio", associado ao trabalho de pesquisa de campo, onde, mediados pelos professores, os alunos desta comunidade linguística foram motivados a exercer a autonomia como pesquisadores.

Para Gadotti (2009) é necessário mapear o potencial educativo de uma comunidade e integrá-lo à sala de aula, por meio de atividades sociais, culturais, econômicas e políticas. Trata-se de ampliar os espaços de aprendizagem em parceria com a comunidade. Para Freire (1996, p. 25) "ensinar não é apenas transferir conhecimento, mas criar possibilidades para a sua produção ou a sua construção".

$3^{\circ}$ Momento: Trabalhando os gêneros textuais "causo e notícia"

Após estudarem a diferença entre causos e notícias, perguntamos aos alunos se já ouviram causos contados por seus pais ou avós. Causos são narrativas orais conservadas e transmitidas de geração para geração, uma história representando fatos verídicos ou não, sempre contados de forma engraçada, com objetivo lúdico. São histórias fantásticas que podem ser engraçadas ou assustadoras.

$4^{\circ}$ Momento: Apresentando o gênero Memórias

Neste momento os alunos iniciaram o trabalho de pesquisa. Solicitamos que entrevistassem seus pais ou avós e que registrassem em seu caderno um "causo" 
contado por um membro antigo de sua comunidade, além disso, recontaram oralmente o causo para os colegas em uma roda de conversas em sala de aula.

$5^{\circ}$ Momento: Pesquisa de campo

Nesta etapa os alunos serão motivados a exercer a autonomia como pesquisadores, com objetivo de realizar a primeira sondagem da comunidade investigada, elaboramos um roteiro com questões pertinentes a cerca da temática pesquisada.

Dividimos a turma em dois grupos, que orientados pela professora entrevistaram dois membros antigos da comunidade remanescente quilombola de Furnas do Dionísio, localizada na área rural do município de Jaraguari/MS, neste estudo chamados de guardiões das memórias, sobre as seguintes temáticas: narrativa sobre a história da comunidade e narrativa sobre a memória escolar. As narrativas de memórias foram filmadas e gravadas em áudio, para que posteriormente sejam transcritas pelos alunos.

$6^{\circ}$ Momento: Transcrição das memórias

Exemplo 1 - Memórias Dona Deti

[...] Teve uma época aqui na Furna se agente falava no Dionísio, aí não tem nada a ver com Dionísio... Gente, o passado uma pessoa sem história, eu acho que não existe ninguém sem história. Por que ou você teve uma história boa ou ruim mais é a sua história [...]

[...] essa Deti veia aqui ó....que vai fica com vontade que chega alguém na casa dela das criança conversa... num é só assunto de jovem... essa criação que tá tendo hoje que é só jovem conversa com jovem... isso ai é uma mau criação ocêis tem que conversa com idoso... ocêis que tem vó que tem tia vai na casa da tia num é a tia Deti que ocêis num gosta dela... num tem importância.... mas é obrigado o jovem visita o idoso... porque o dia do amanhã vai se vocêis... já penso? Se na casa você vê e morre sua muié e você fica lá oiando pras parede sem te ninguém pra conversa... o jovem num tem importância ocêis sai esse tanto de jovem ai visita um idoso... isso nóis fazia quando nóis era jovem... as veis nóis juntava um monte de moça e ia lá no tio Davi... ia lá visita o tio Davi... então ele contava cada causo maravilhoso pra nóis... si nóis sabe desses causo é porque eles contava... não tinha televisão não tinha nada então eles contava esses causo ai [...](Memórias Dona Deti).

$7^{\circ}$ Momento: Retextualização das memórias

Com base nos operadores discursivos apresentados por Marcuschi, em duplas os alunos da turma de $9^{\circ}$ ano da Escola Estadual Zumbi dos Palmares retextualizaram as memórias transcritas no $6^{\circ}$ momento.

Exemplo 1 - Memórias retextualizadas por um aluno do $9^{\circ}$ ano

[...] Existiu uma época aqui em Furnas que não podia falar no nome do Dionísio, ninguém queria assumir sua origem. Não existe uma pessoa sem história, seja ela boa ou ruim, mas é a sua história [...]

[...] Essa Deti velha já ficou com muita vontade de receber em casa uma criança para conversar. Não existe só assunto de jovem. Essa criação de hoje, que jovem só pode conversar com jovem, é uma mau criação de vocês. Tem que conversar com o idoso. Vocês que tem vó, tia vai visitar. Não é a tia Deti que vocês não gostam, não tem importância. Mas é importante o jovem visitar o idoso. Por que amanhã será você um idoso. Já pensou? Se morre sua mulher e você fica olhando para as paredes sem ter ninguém para conversar. Não tem importância sair um grupo de jovens para visitar um idoso. Isso nós fazíamos quando éramos jovens. Ás vezes nós juntávamos um monte de moças para visitar o tio Davi. Então ele contava cada causo maravilhoso. Sabemos destes causos por que eles contavam, não tinha televisão, não tinha nada. Então eles contavam esses causos [...](Memórias Dona Deti).

$8^{\mathrm{o}}$ Momento: Apontar instrumentos para superar os problemas da primeira produção

Neste artigo apresentamos apenas uma produção textual dos alunos com objetivo de demonstrar o trabalho didático nas aulas de Língua Portuguesa, com os operadores discursivos - OD propostos por Marcuschi (2010) e retextualizados para o gênero memórias. As descrições minuciosas dos OD, das memórias retextualizadas estão em processo de análise e serão apresentadas na dissertação final do Programa de Mestrado Profissional em letras em rede - PROFLETRAS, intitulada "Atividades de retextualização a partir do gênero discursivo memórias: proposta de trabalho em uma escola da comunidade remanescente quilombola de Furnas do Dionísio". 


\section{Considerações Finais}

Quando nos propusemos a trabalhar o registro das histórias orais nos preocupamos em resguardar e valorizar os membros desta comunidade, visto que, durante as entrevistas in loco, que antecederam a aplicação da sequência didática e do trabalho a campo, observamos, por diversas vezes, o dissabor sobre pesquisadores anteriores que vieram à comunidade para extrair informações e não retornaram para apresentar os resultados obtidos, devemos chamar atenção para a "atitude colonizadora".

O trabalho com as narrativas de memória de uma comunidade étnica permite penetrar em seu universo cultural, enraizado de conhecimentos tradicionais e constituintes da sua formação identitária. As narrativas orais podem ser consideradas de cunho interdisciplinar por instigar novas discussões e interpretações que são relevantes para os estudiosos da área de ciências humanas e linguagens.

Este é um trabalho em processo de construção, um estudo articulado, interdisciplinar e integrado entre professores, guardiões das memórias e alunos membros desta comunidade linguística. Desde o início deste estudo, agosto de 2016 escrevemos vários esboços de projetos e sequencias didáticas, que foram implementados ou modificados conforme necessidades de suporte teórico ou aplicação prática.

\section{REFERÊNCIAS}

BAKHTIN, M. Estética da Criação Verbal. Trad. Maria E. Galvão e revisão por Marina Appenzeller. 3. ed. São Paulo: Martins Fontes, 2000.

Marxismo e filosofia da linguagem: problemas fundamentais do método sociológico na ciência da linguagem. Trad. Michel Lahud e Yara F. Vieira. 11. ed. São Paulo: Hucitec, 2004.

Estética da criação verbal. Introdução e tradução do russo de Paulo Bezerra. 6. ed. São Paulo: Martins Fontes, 2011

BANDEIRA, Maria de Lourdes; DANTAS, Triana de Veneza Sodré. Relatório Antropológico. Furnas de Boa Sorte, MS. Projeto de Mapeamento e Sistematização das Áreas Remanescentes de Quilombo (Ministério da Cultura/Fundação Cultural Palmares). Campo Grande: Idaterra, 1997.

BRASIL. Constituição da Republica Federativa do Brasil. Brasília: Senado, 1988. BRASIL. Lei $\mathbf{n}^{\mathbf{0}}$ 10.639, de 9 de Janeiro de 2003. Diário Oficial da União de 10 de Janeiro de 2003; Brasília, DF.

BRASIL, MINISTÉRIO DA EDUCAÇÃO. Diretrizes Curriculares Nacionais para a Educação das Relações Étnico-Raciais e para o Ensino de História e Cultura AfroBrasileira e Africana. Outubro, 2004

BRASIL. Decreto Presidencial 4.887/2003 de 20 de novembro de 2003. Regulamenta o procedimento para identificação, reconhecimento, delimitação, demarcação e titulação das terras ocupadas por remanescentes das comunidades de quilombos de que trata o art. 68 do Ato das Disposições Constitucionais Transitórias. Em: Diário Oficial da União, EDIÇÃO NÚMERO 227 DE 21/11/2003.

CASTORIADIS, Cornelius. A instituição imaginária da sociedade. Tradução Guy Reynaud. Revisão Técnica de Luiz Roberto Salinas Fortes. - Rio de janeiro: Paz e Terra, 1982. ( Coleção Rumos da Cultura Moderna, Volume 52);

DOLZ, Joaquim; SCHNEUWLY, Bernand. Gêneros orais e escritos na escola. Campinas, SP: Mercado de Letras, 2004. 278 p. (Tradução e organização: Roxane Rojo; Glaís Sales Cordeiro). 
DOLZ, B.; NAVERRAZ, M. Sequências didáticas para o oral e a escrita: apresentação de um procedimento. Gêneros orais e escritos na escola. Tradução e organização de R. Rojo e G. L. Cordeiro. Campinas: Mercado de Letras, 2004. p. 95128.

DOLZ, B.; SCHNEUWLY, D. Gêneros e progressão em expressão oral e escrita: elementos para reflexões sobre uma experiência suíça (francófona). Gêneros orais e escritos na escola. Tradução e organização de R. Rojo e G. L. Cordeiro. Campinas: Mercado de Letras, 2004. p. 41-70.

FREIRE, Paulo. Pedagogia da autonomia : saberes necessários à prática educativa. 8. ed. São Paulo : Paz e Terra, 1996.

FUNDAÇÃO CULTURAL PALMARES. Clipping mês da Consciência Negra. Disponível em http://www.palmares.gov.br/

GADOTTI, Moacir. Boniteza de um sonho: ensinar-eaprender com sentido. São Paulo: Editora e Livraria Instituto Paulo Freire, 2009. (Educação Cidadã, 2).

MARCUSCHI, L.A. Da Fala para a Escrita: Atividades de Retextualização. São Paulo: Cortez, 2010.

Produção de texto, análise de gêneros e compreensão. São Paulo: Parábola Editorial, 2008.

MATENCIO, M. L. M. Atividades de (re)textualização em práticas acadêmicas: um estudo do resumo. Scripta, Belo Horizonte: PUC, v. 6, n. 11, p. 109-122, 2002

TRAVAGLIA, L. C. Concepções de linguagem. In: . Gramática e interação: uma proposta para o ensino de gramática no $1^{0}$ e $2^{\circ}$ graus. São Paulo: Cortez, 1996.

Recebido em: junho de 2017.

Aprovado em: julho de 2017.

Como citar este trabalho:

FRANCISCHINI, A, W. de F.; BARROS, A. L. DE C. C. Atividades de retextualização a partir do gênero discursivo memórias: proposta de trabalho em uma escola da comunidade remanescente quilombola de Furnas do Dionísio. Traços de linguagem, v. 1, n. 1, p. 57-66, 2017. 